ISN $=800717$

Bibliotheek

Proesstation voor de Groenten- en

Fruitceit onder Glas te Naaidrilit 


\title{
A UNIVERSAL METHOD FOR PREPARING NUTRIENT SOLUTIONS OF A CERTAIN DESIRED COMPOSITION
}

\author{
by ABRAM A. STEINER \\ Horticultural Experiment Station, Naaldwijk, Netherlands
}

\section{INTRODUCTION}

Water cultures, or other ways of soil-less plant culture, e.g. sand cultures, are frequently used for physiological research. Reference to the literature however, reveals a considerable diversity in the composition of the nutrient solutions used. Hewitt ${ }^{2}$ gives over a hundred formulae, and Schropp ${ }^{4}$ about sixty, excluding those prescribed for inducing deficiency symptoms. The development of practical soil-less culture techniques before the last war gave rise to a veritable avalanche of formulae. Up to the present time, a total of about three hundred formulae have been published, many of which have been particularly recommended for the growth of particular crops, e.g. tomatoes, carnations, roses etc.

Physiological experiments on nutrition have been made to investigate, among other things, the influence of a wide range of nutrient-solution composition on the development and behaviour of plants. For experiments of this kind, knowledge of the problems underlying the preparation of the desired nutrient solutions is a first prerequisite since the actual composition may not always correspond to that given by the formula. For example, there are many solutions, the formulae for which indicate the presence of much more phosphate, sulphate, calcium, and magnesium than can be determined by analysis; thus, from two solutions which, according to their formulae, should both contain say, $2 \mathrm{mg}$ ions of phosphate per litre, $1.8 \mathrm{mg}$ ions may be recovered from one, and only $0.2 \mathrm{mg}$ ions from the other. This is due to the fact that the 
great majority of recommended formulae are not realizable in solution because the solubility products of certain ion combinations are exceeded. The interpretation of experiments involving such cases would therefore, be seriously affected. The main object of the present investigation is to find a solution to these problems.

Although presenting no direct problems per se, it must also be noted that very divergent formulae may produce nutrient solutions of identical composition, e.g. $2 \mathrm{mmol} \mathrm{Ca}\left(\mathrm{NO}_{3}\right)_{2}$ and $4 \mathrm{mmol} \mathrm{KH_{2 }} \mathrm{PO}_{4}$ give exactly the same concentrations of $\mathrm{K}^{+}(4 \mathrm{me}), \mathrm{Ca}^{++}(4 \mathrm{me})$, $\mathrm{NO}_{3}{ }^{\prime}$ (4 me) and $\mathrm{H}_{2} \mathrm{PO}_{4}{ }^{\prime}$ (4 me) as $4 \mathrm{mmol} \mathrm{KNO}_{3}$ and $2 \mathrm{mmol}$ $\mathrm{Ca}\left(\mathrm{H}_{2} \mathrm{PO}_{4}\right)_{2}$ : this is clearly seen when the ions are considered individually.

Judging from their publications and statements, it would seem that many investigators have grown crops in a solution chosen largely at random, and that, where the results have been successful, they have recommended that solution as being specific for the particular crop concerned. Comparisons between different solutions as to their effect on crop growth have, in fact, been made only to a limited extent, whilst where they occur, precipitates render the corresponding formulae invalid as a guide to actual composition: this latter applies to many experiments in which comparisons have been made between different formulae. ${ }^{3}$ Furthermore, the observation that a crop grows well in a particular nutrient solution does not prove that there is not a more favourable composition for that crop.

Since the plant itself excercises certain selective properties, the question may be raised as to the extent to which the composition of the nutrient solution is important for growth and development. However, before pursuing this point further, it is necessary to examine more closely what is meant by "chemical composition". This term comprises (1) the concentrations of the component ions, (2) the total ionic concentration, and (3) pH. Experiments with flowing cultures, in which fresh nutrient solution is supplied continuously to plants, have shown that individual ions are taken up even at very low concentrations, but it is probable that for every ion, there is a certain minimum concentration below which uptake is no longer possible at the required rate. At the other extreme of concentration, luxury consumption may lead to internal toxicity. The point at issue here is whether there is an optimum 
concentration of certain ions in solution for a certain crop grown under given environmental conditions, or whether their relative proportions and not absolute concentrations are the determining factors?

Let us assume that absolute concentrations are decisive and that in a particular experiment, optimum concentrations have been found corresponding to $a$ me $\mathrm{K}^{+}, b$ me Ca++ and $c$ me $\mathrm{Mg}^{++}$per litre. This gives the ratio of $\mathrm{K}: \mathrm{Ca}: \mathrm{Mg}$ as $\mathrm{a}: \mathrm{b}: \mathrm{c}$. However, this ratio may also be expressed as $a / n b / n c / n$, provided the value of $\mathrm{a}+\mathrm{b}+\mathrm{c}$ is given; thus, the optimum composition can be expressed in terms of both a sum and a ratio. The point is that even if the absolute concentrations are considered to be determining factors, the relative proportions of the different ions can also be considered in the same way, if the total ionic concentration is included.

From the author's own investigations along these lines on carnations, tomatoes, and gerberas, it appeared that the relative proportions of the anions were important only within rather wide limits but that the relative proportions of the cations were very important. The total ion concentration is important within the limits \pm 0.2 atmospheres osmotic pressure. In many cases, the $\mathrm{pH}$ of the nutrient solution was important within the limits $\pm 0.2 \mathrm{pH}$ units.

In the author's opinion, it is essential that in physiological research involving water cultures, the influence of the composition of the nutrient solution be investigated systematically. In order to do this, every possible combination of the variables, anion ratio, cation ratio, total ionic concentration, and $\mathrm{pH}$ must be considered.

Superficially, the preparation of nutrient solutions satisfying certain requirements would appear to be straightforward. This however is by no means the case; the $\mathrm{pH}$ of the solution, a very important growth factor, introduces serious complications. For example, let us assume that a solution of a certain desired composition has a $\mathrm{pH}$ of 5 , but that we require a $\mathrm{pH}$ of 6.5 . This can be achieved by adding an alkali such as $\mathrm{KOH}$. However, a great dcal of $\mathrm{KOH}$ may be required, especially if the solution contains a large amount of phosphate. At $\mathrm{pH} 5$, practically all the phosphate is present as $\mathrm{H}_{2} \mathrm{PO}_{4}^{-}$, as shown by the phosophate dissociation curve ${ }^{1}$ in Figure 1: in order to obtain a $\mathrm{pH}$ of $6.5,22$ per cent of this 
$\mathrm{H}_{2} \mathrm{PO}_{4}{ }^{-}$must be converted into $\mathrm{HPO}_{4}^{--}$, according to the dissociation sequence, $\mathrm{H}_{3} \mathrm{PO}_{4} \rightleftharpoons \mathrm{H}_{2} \mathrm{PO}_{4}{ }^{-} \rightleftharpoons \mathrm{HPO}_{4}{ }^{--} \rightleftharpoons \mathrm{PO}_{4}{ }^{--}$. The large amount of $\mathrm{KOH}$ required for this would therefore, seriously upset the relative proportions of the cations. The answer would be to

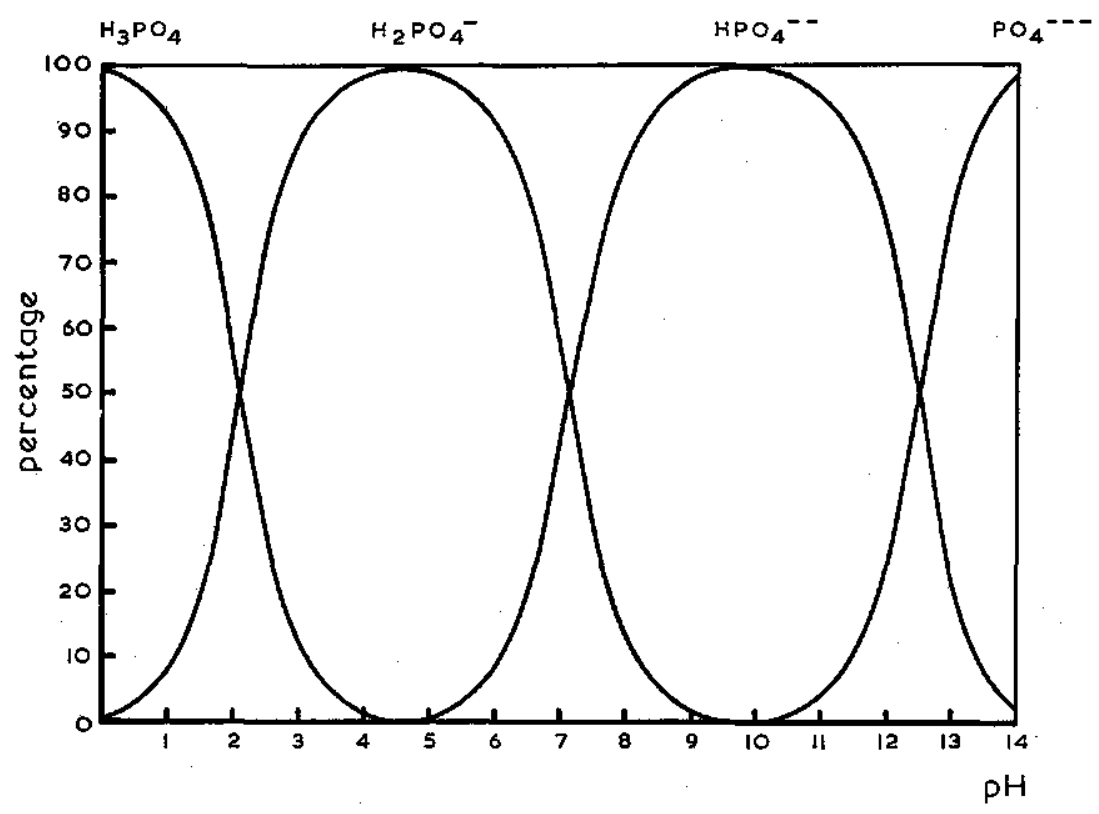

Fig. 1. Phosphate dissociation curve.

adjust the $\mathrm{pH}$ by titrating with alkali containing all cations in the same relative proportions as in the original solution; in this case however, the appropriate mixture of $\mathrm{KOH}+\mathrm{Mg}(\mathrm{OH})_{2}+\mathrm{Ca}(\mathrm{OH})_{2}$ will only yield a sufficiently dissociated solution of $\mathrm{Ca}^{++}$and $\mathrm{Mg}^{++}$ at extremely low concentration.

As an alternative, the desired solution could be prepared with a $\mathrm{pH}$ of over 7 by supplying the phosphate as $\mathrm{PO}_{4}^{--}$and then titrating to the required $\mathrm{pH}$ with a mixture of all anions in the same relative proportions as before. The difficulty with this procedure, as will appear later, is that at $\mathrm{pH} \mathrm{7,} \mathrm{only} \mathrm{a} \mathrm{limited} \mathrm{number} \mathrm{of} \mathrm{ion}$ combinations are possible without producing a precipitate (e.g. of $\mathrm{CaHPO}_{4}$ ) at an osmotic pressure of $0.7 \mathrm{~atm}$. Since the optimum for many crops must surely not be below $0.7 \mathrm{~atm}$, this method can only be used to a limited extent. Titration with a solution already 
containing phosphate precipitates will obviously yield very unreliable results because of the low dissolution rates of these phosphates.

The aim of this paper is to determine how a particular nutrient solution can be prepared which satisfies given requirements as to (1) relative cation ratios, (2) relative anion ratios, (3) total ionic concentration, and (4) $\mathrm{pH}$. However, before this problem is considered further, it was thought desirable to investigate how these requirements are met in manurial trials on soils and to what extent, the position can be improved in these cases.

\section{COMPARATIVE MANURIAL TRIALS ON SOILS}

If one wishes to investigate, for example, the effect of an addition of potassium to the soil on the development of a particular crop, it is clear that this cannot be realised without introducing other factors, e.g. chloride or sulphate. Potassium, at least, must be added as a salt. Although one is inclined to attribute a resulting response to the cation in question, in this case potassium, it may be that the chloride or the sulphate is also involved, besides the increase in the total ionic concentration. Because of the high buffering capacity of the soil, changes in $\mathrm{pH}$ do not usually cause trouble.

It is however, possible to avoid these difficultics. One can investigate the influence of potassium with respect to another cation, i.e. by working with relative quantities; as already suggested in the introduction to this paper, this is justified even though only "absolute quantities" are evaluated. Thus, in one case, $\mathrm{K}_{2} \mathrm{SO}_{4}$ may be used and in the other, an equivalent amount of $\mathrm{Na}_{2} \mathrm{SO}_{4}$; variation can be achieved by supplying the same total quantity of sulphate but distributed to different extents between $\mathrm{K}_{2} \mathrm{SO}_{4}$ and $\mathrm{Na}_{2} \mathrm{SO}_{4}$. In this way both the effects of different levels of sulphate and of different total ionic concentrations can be eliminated.The latter, of course, is only possible completely, if salts containing cations of the same valency are used; if in one case, 2 gramequivalents of $\mathrm{SO}_{4}{ }^{\prime \prime}$ are supplied as $\mathrm{MgSO}_{4}$, and in the other as $\mathrm{K}_{2} \mathrm{SO}_{4}$, the former yields 2 gramions and the latter 3 gramions, consequently resulting in a difference in total ionic concentration, though to a smaller extent than with conventional methods.

Curiously enough, the importance of the above does not appear to have been generally appreciated to any real extent. Take for example, experiments involving $\mathrm{K}: \mathrm{N}$ ratios. If these are made using different amounts of $\mathrm{K}_{2} \mathrm{SO}_{4}$ and $\mathrm{Ca}\left(\mathrm{NO}_{3}\right)_{2}$, their interpretation is not at all straightforward; although only the $\mathrm{K}: \mathrm{N}$ ratio is usually considered, there are actually four factors to be taken into account $-\mathrm{K}^{+}: \mathrm{NO}_{3}{ }^{-}, \mathrm{K}^{+}: \mathrm{Ca}^{++}, \mathrm{Ca}^{++}: \mathrm{SO}_{4}{ }^{--}$ and $\mathrm{NO}_{3}{ }^{-}: \mathrm{SO}_{4}{ }^{--}$. This complication may be eliminated by applying nitro-gen as the ammonium ion. Thus, for the purposes of comparison, the same total amount of $\mathrm{K}_{2} \mathrm{SO}_{4}+\left(\mathrm{NH}_{4}\right)_{2} \mathrm{SO}_{4}$ is applied, with the ratio 
$\left(\mathrm{NH}_{4}\right)_{2} \mathrm{SO}_{4}: \mathrm{K}_{2} \mathrm{SO}_{4}$ different in every treatment; in this case it is clear that provided that differences in nitrification do not interfere with the results, a valid test is being made of the $\mathrm{NH}_{4}{ }^{+}: \mathrm{K}^{+}$ratio. If $\mathrm{NH}_{4} \mathrm{NO}_{3}$ is used for increasing the $\mathrm{N}: \mathrm{K}$ ratio however, the total ionic concentration is affected; it must also be pointed out that on certain soils, the use of ammonium salts in such experiments may lead to considerable changes in $\mathrm{pH}$.

Many more difficulties are encountered in manurial experiments on soils, but the few examples given above serve the purpose of illustration.

\section{THE PROBLEM WITH NUTRIENT SOLUTIONS}

Let us now take the case of a nutrient solution corresponding to a particular formulation, in which the potassium content is to be varied. This may be done by the addition of extra potassium but it is clearly impossible to do this without affecting the $\mathrm{pH}$. In order to maintain the $\mathrm{pH}$ at a desired value, the addition of an anion is essential, e.g. sulphate or chloride. As a result of this, of course, the effect of the sulphate or chloride must be considered besides that of the potassium. In the case of nitrogen, attempts can be made to avoid this effect by adding $\mathrm{NH}_{4} \mathrm{NO}_{3}$, but many plants react differently to nitrogen when supplied as nitrate or ammonium ion; also, because of the more rapid uptake of ammonium by the plant, there may follow an appreciable drop in $\mathrm{pH}$, in which case, if the $\mathrm{pH}$ is to be maintained, a cation must be added which may interfere with the experiment.

Systematic research into the influence of the chemical composition of the nutrient solution is only justified if one deals with relative ratios of the nutrients. There is no objection whatsoever to this approach. As already discussed in the introduction, whatever the values assigned to the "absolute" levels, it is still possible to use relative ratios, provided that the total ionic concentration and also the $\mathrm{pH}$, are taken into account. This does not imply, as was suggested in the previous discussion on soil, that $\mathrm{K}_{2} \mathrm{SO}_{4}$ can be replaced by $\mathrm{Na}_{2} \mathrm{SO}_{4}$; in both cases, the total ionic concentration is increased.

Consideration of the ratio, $\mathrm{N}$ (as $\left.\mathrm{NO}_{3}\right): \mathrm{P}: \mathrm{S}: \mathrm{K}: \mathrm{Ca}: \mathrm{Mg}$ is meaningless since the ratio $\left[\mathrm{N}\left(\mathrm{as}_{3}\right)+\mathrm{P}+\mathrm{S}\right]:[\mathrm{K}+\mathrm{Ca}+\mathrm{Mg}]$ is already determined by the $\mathrm{pH}$. Hence one must deal with different relative ratios of anions in combination with different relative ratios of cations. Many people attach great importance to the $\mathrm{K} / \mathrm{N}$ ratio; although the significance of this is open to argument $\mathbf{5}$, it can also be considered on the basis of relative ratios, since high $\mathrm{K}^{+}$ relative to the other cations and low $\mathrm{NO}_{3}{ }^{-}$relative to the other anions means the same as a high $\mathrm{K} / \mathrm{N}$ ratio. In principle, using a 
systematic approach, it is desirable to take into account as many cations and anions as possible. In this article attention has been rectricted to the anions, $\mathrm{NO}_{3}^{-}, \mathrm{H}_{2} \mathrm{PO}_{4}^{-}\left(\mathrm{HPO}_{4}^{--}\right.$and $\left.\mathrm{PO}_{4}^{---}\right)$and $\mathrm{SO}_{4}^{--}$and to the cations, $\mathrm{K}^{-}, \mathrm{Ca}^{+!}$and $\mathrm{Mg}^{++}$.

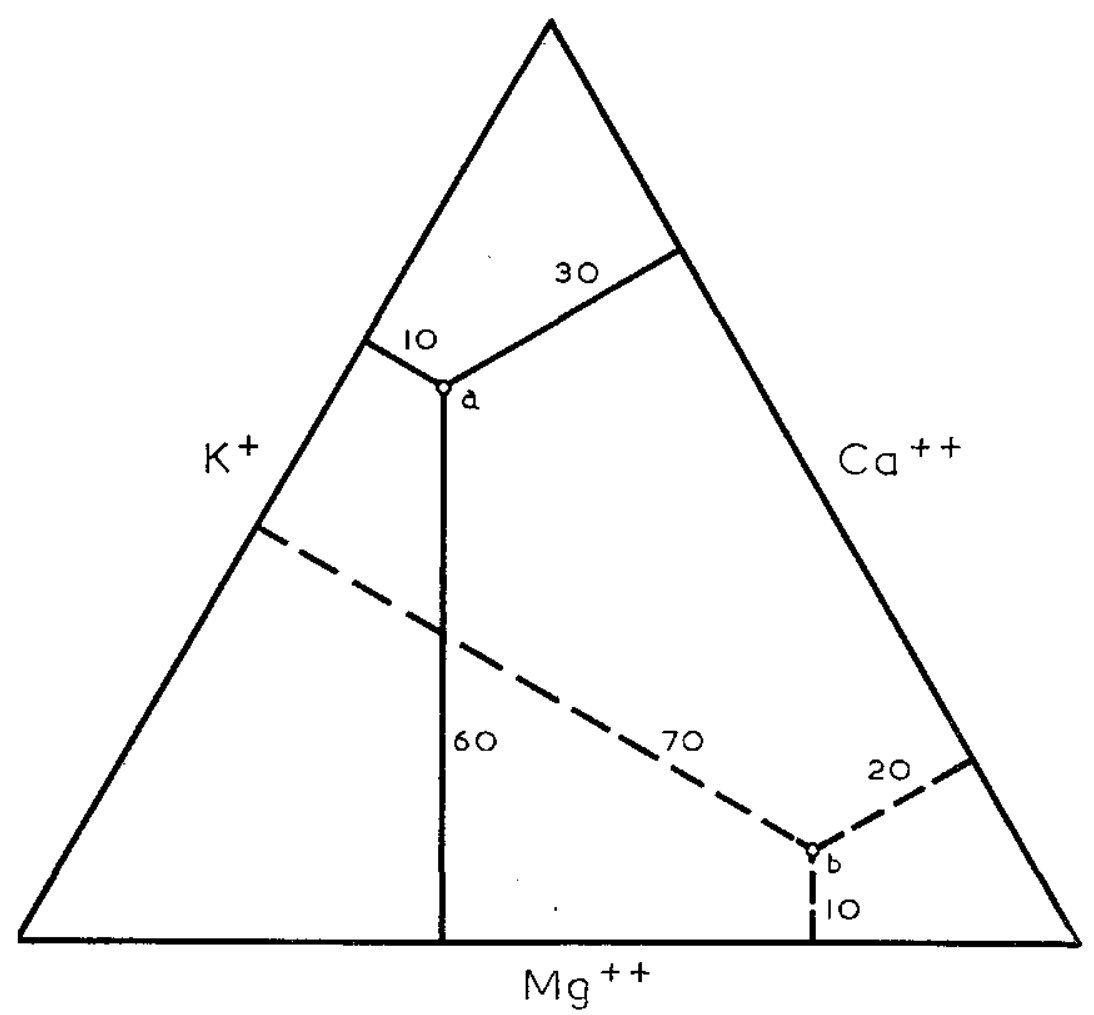

Fig. 2. $\mathrm{K}^{+}: \mathrm{Ca}^{++}: \mathrm{Mg}^{-+}$ratios represented by the points $\mathrm{a}$ en $\mathrm{b}$.

The representation of relative ratios as single points within a triangular system offers considerable advantages. This can be done by making the ratios correspond to the length of the perpendiculars from each point to the 3 sides of an equilateral triangle, each side representing the proportions of a particular ion (cf Fig. 2); the ratio of the 3 ions is then easily determined by reference to the relative positions of the points within the triangle. For convenience, each side is divided into 10 equal parts and a triangular co-ordinate system imposed. Referring to Figure 3 , every point on the side $\mathrm{AB}$ for example corresponds to 0 per cent $\mathrm{Mg}^{++}$, those on the line 
CD to 20 per cent $\mathrm{Mg}^{++}$, and so on; point $N$ corresponds to a ratio of 20 per cent $\mathrm{K}^{+}, 30$ per cent $\mathrm{Ca}^{++}$, and 50 per cent $\mathrm{Mg}^{++}$. Naturally one can consider each ratio (or point) as a ratio of weights, as an ion ratio, or as an equivalent ratio. Because of the connection with

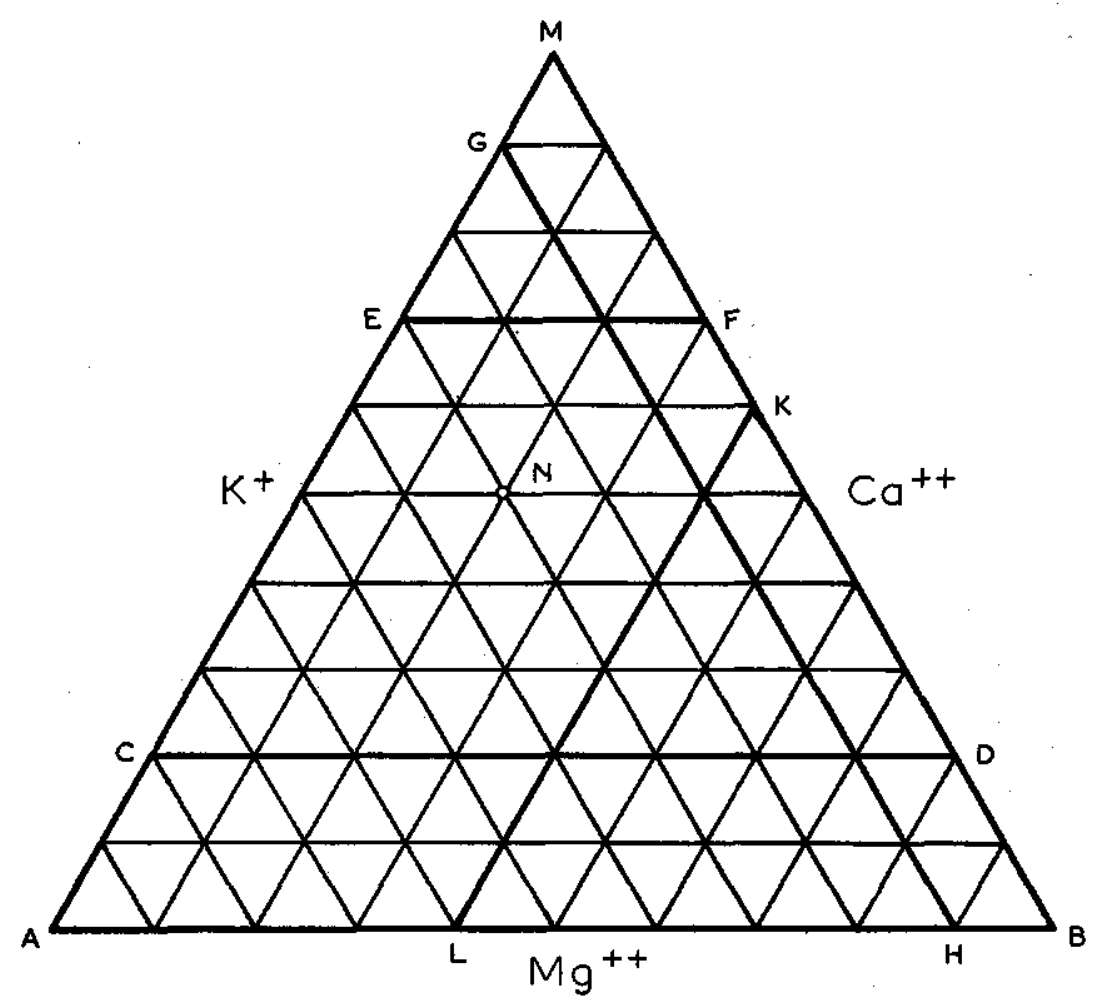

Fig. 3. Triangular graph used for comparing the $\mathrm{K}^{+}: \mathrm{Ca}^{++}: \mathrm{Mg}^{++}$ratios.

pH adjustments to be discussed later, we prefer equivalent ratios. By locating all points within a cation and an anion triangle and combining one from each, it is possible to classify systematically, all possible nutrient combinations.

For nutritonal-physiological investigations each combination must correspond to a particular "formula" according to which a certain ionic concentration and a certain $\mathrm{pH}$ are obtainable without affecting the particular ratio used. Satisfying the $\mathrm{pH}$ requirement represents a serious stumbling block. For example, let us assume that nutrient solutions are to be prepared according to two formu- 
lae giving a particular total ionic concentration. If all the phosphate is supplied as $\mathrm{H}_{2} \mathrm{PO}_{4}^{-}$, the solutions will have low $\mathrm{pH}$ values (about 5). Higher $\mathrm{pH}$ values may be obtained by titration with $\mathrm{KOH}$, but then the $\mathrm{K}: \mathrm{Ca}: \mathrm{Mg}$ ratio must be readjusted i.e. the amount of $\mathrm{KOH}$ required must be converted into the same $\mathrm{K}: \mathrm{Ca}: \mathrm{Mg}$ ratio as in the original solution; at the same time, the total ionic concentration, increased by the titration, has also to be restored. The result is that the $\mathrm{pH}$ is no longer the same as immediately after the titration.

The problem of this $\mathrm{pH}$ change calls for a theoretical treatment of incomplete dissociation and $\mathrm{pH}$ with regard to $\mathrm{CaHPO}_{4}, \mathrm{MgHPO}_{4}$, $\mathrm{Ca}(\mathrm{OH})_{2}$ and other compounds. This is beyond the scope of the present article and will not be discussed here. The result of such a treatment however, indicates that there must be a systematic relation between the amount of $\mathrm{OH}$ ions required to give the desired $\mathrm{pH}$, the absolute concentration of phosphate and certain cation ratios in the solution.

It will be seen later that by means of certain curves, it is possible to fit into a formula, any chosen combination and that in this way, the following requirements can be satisfied with considerable accuracy: -

(1) a particular relative cation ratio

(2) a particular relative anion ratio

(3) a particular total ionic concentration

and (4) a particular $\mathrm{pH}$.

Since the actual course of these curves in such a system has to be determined experimentally, a large number of solutions must be prepared.

\section{REQUIRED COMBINATIONS OF ION RATIOS, TOTAL IONIC CONCENTRATION AND PH}

Even supposing the approach described above was not entirely successful, the formulae obtained may yet find application to physiological studies on nutrition. For example, it would be possible to make a selection from those formulae giving a suitable $\mathrm{pH}$, even if this did not exactly correspond to the one required. It was therefore considered desirable to include in this investigation, a large number of 'combinations'; these would also provide an even better basis for the construction of the above-mentioned curves. 
Following this principle, we have tried to include as many ratios as possible; assuming 50 for the anions and 50 for the cations, this gives us $50 \times 50$ $=2,500$ possible combinations. If, in addition to these, we wish to include say, 5 different total ionic concentrations and 5 different $\mathrm{pH}$ values, the total number of solutions required would be 62,500 . Although these will include many combinations that can be rejected on theoretical grounds because of expected precipitates, there still remains too large a number to be dealt with in practice. The number of ratio combinations must therefore be reduced or certain ranges of ratios within the triangle omitted. The phosphate content of nutrient solutions used in practice, expressed as milliequivalents * $\mathrm{H}_{2} \mathrm{PO}_{4}^{-}$, generally does not exceed 25 per cent of the total content of anions.

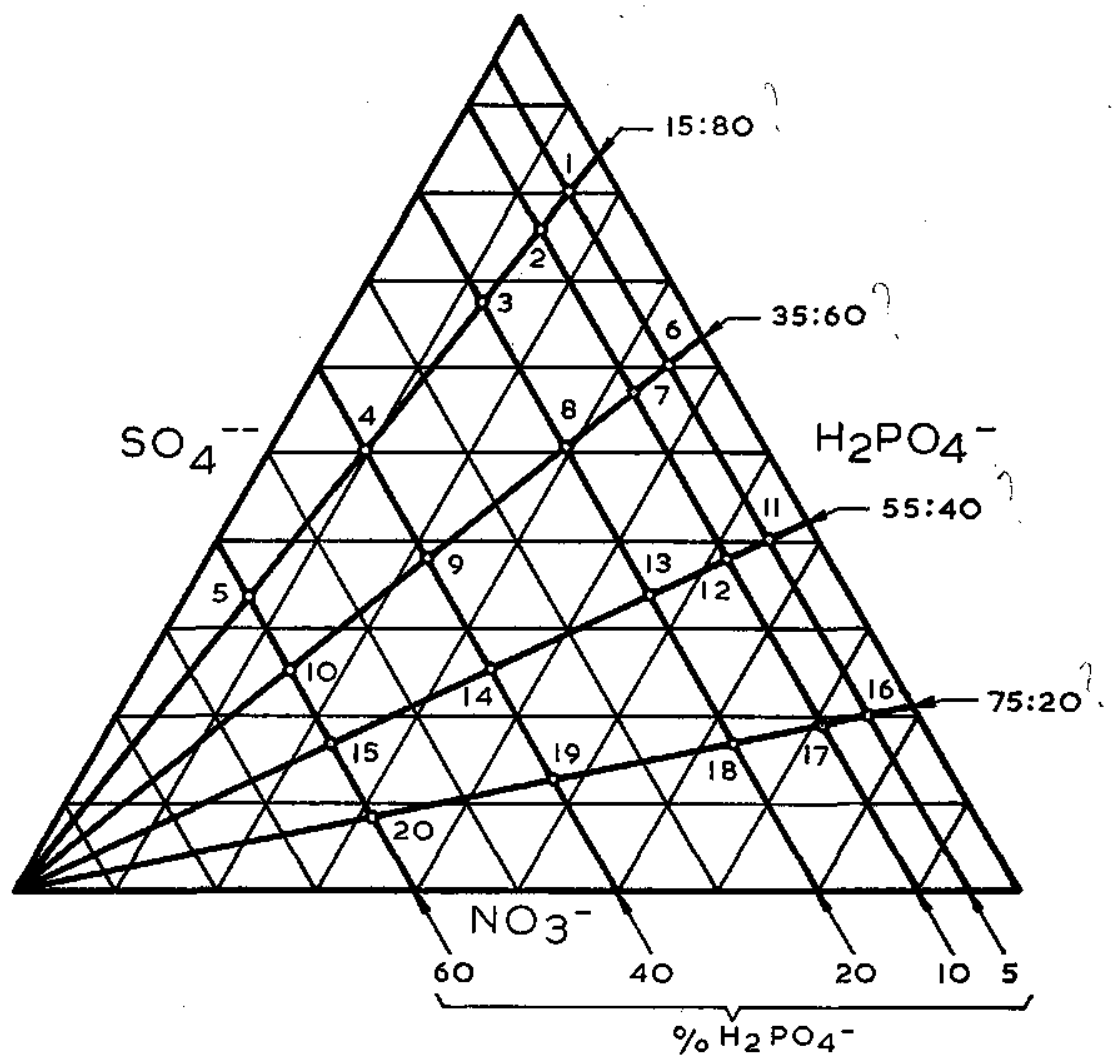

Fig. 4. The anion ratios used in the investigation. Combinations 1 to 20 .

* In this article, phosphate is always expressed as milliequivalents-percent, or as milliequivalents (me) of $\mathrm{H}_{2} \mathrm{PO}_{4}$ even though, depending on the $\mathrm{pH}$, it may be partly present as $\mathrm{HPO}_{4}$. Thus, although the addition of $2 \mathrm{me} \mathrm{H}_{2} \mathrm{PO}_{4}$ to a solution may for example, yield $1 \mathrm{me} \mathrm{H}_{2} \mathrm{PO}_{4}{ }^{\prime}$ and 2 m.e. $\mathrm{HPO}_{4}{ }^{\prime \prime}$, this still amounts to $2 \mathrm{mg}$ ions of phosphate. Confusion will be avoided if the phosphate is always expressed as me of $\mathrm{H}_{2} \mathrm{PO}_{4}$. 
Although it is not desirable to exclude entirely the higher proportions of phosphate because thesc may be of fundamental physiological interest, attention can be largely directed to the lower proportions. In any case, high proportions of phosphate will allow for only a few combinations because of precipitation $e . g$. of $\mathrm{CaHIO}_{4}$.

To begin with we have chosen phosphate contents corresponding to the $5,10,20,40$, and 60 per cent lines in Figure 4. Combined with four different $\mathrm{NO}_{3}{ }^{-}: \mathrm{SO}_{4}{ }^{--}$ratios, viz $80: 15,60: 35,40: 55$ and $20: 75$, these give 20 different anion combinations (Nos. 1 to 20, Fig. 4). The 16 cation ratios chosen for investigation are shown in Figure $5(a-p)$; since it is already known that best results are obtained with low proportions of $\mathrm{Mg}$, attention has been mainly focussed on these.

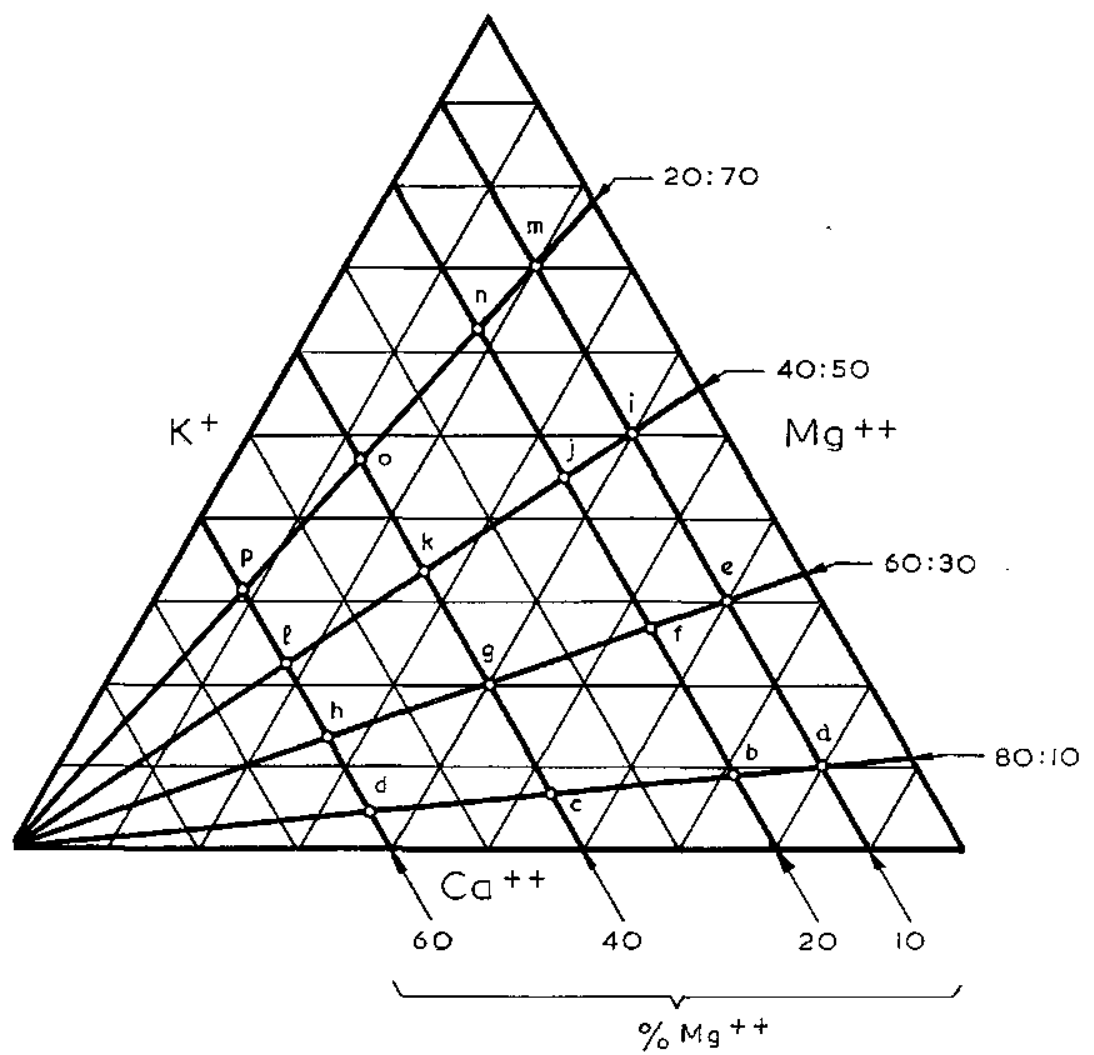

Fig. 5. The cation ratios used in the investigation. Combinations a to $\mathrm{p}$.

The 20 anion ratios and 16 cation ratios together yield 320 combinations. With 5 different pH-values included, namely 5.0,5.8,6.5, 7.1, and 7.6, the total amounts to 1600 different combinations.

Obviously, if the effects of different ionic ratios are to be distinguished, 
the total 'strengths' of the solutions must be comparable. This raises the question as what "strength" actually means to the plant. Clearly it is not the weight of the salts but their ionic equivalents; to some people however this is a disputable matter. However, the calculations necessary to ensure comparable total equivalent contents become very complicated, especially when allowance has to be made for adjustments to the $\mathrm{pH}$ value by titration; among other factors, this is bound up with the phosphate dissociation series, $\mathrm{H}_{3} \mathrm{PO}_{4} \rightleftharpoons \mathrm{H}_{2} \mathrm{PO}_{4}^{-} \rightleftharpoons \mathrm{HPO}_{4}^{--} \rightleftharpoons \mathrm{PO}_{4}^{---}$. Partly because of this complication, but largely due to the fact that earlier experiments with different crops have demonstrated the great importance of total ionic concentration, as reflected in the osmotic values of the nutrient solutions, the total ionic concentration has been kept constant. Because of the already very large number of investigations entailed, we have therefore restricted ourselves to a single concentration, one in which very many plants are known to thrive, corresponding to $0.71 \mathrm{~atm}$ osmotic pressure. Assuming a theoretically ideal complete dissociation at $15^{\circ} \mathrm{C}$, this is equivalent to a total concentration of $30 \mathrm{mg}$ ions per litre, provided no hydrolysis or precipitation occurs.

The 1600 combinations have been incorporated into formulae and subjected to laboratory investigation. A detailed description of their preparation is given below.

\section{PREPARATION OF THE TEST SOLUTION COMBINATIONS}

In order to clarify the procedure employed, full details are given in Table $I$ for the Solution $I a$, corresponding to the Anion Ratio No. $I$ (cf Fig. 4) and Cation Ratio a (cf Fig. 5), with an osmotic pressure of $0.71 \mathrm{~atm}$.

In the Column $(I)$ the equivalent content of each ion is expressed as a percentage of the corresponding total anion or cation

TABLE 1

\begin{tabular}{|c|c|c|c|c|}
\hline Combination & \multicolumn{2}{|c|}{ Ratio } & \multicolumn{2}{|c|}{ Absolute values } \\
\hline Ia & $\begin{array}{l}\text { equiv. in \% } \\
\text { (I) }\end{array}$ & $\begin{array}{l}\text { ions } \\
(2)\end{array}$ & $\begin{array}{c}\text { me per litre } \\
(3)\end{array}$ & $\begin{array}{c}\text { mg ions per litre } \\
\text { (check) } \\
\text { (4) }\end{array}$ \\
\hline $\mathrm{NO}_{3}-$ & 80 & 80 & 13.151 & 13.151 \\
\hline $\mathrm{H}_{2} \mathrm{PO}_{4}^{-}$ & 5 & 5 & 0.822 & 0.822 \\
\hline $\mathrm{SO}_{4}^{--}$ & 15 & \multirow[t]{2}{*}{7.5} & 2.466 & \multirow[t]{2}{*}{1.233} \\
\hline Total & 100 & & 16.439 & \\
\hline $\mathrm{K}^{+}$ & 80 & 80 & 13.151 & 13.151 \\
\hline $\mathrm{Ca}^{++}$ & 10 & 5 & 1.644 & 0.822 \\
\hline $\mathrm{Mg}^{++}$ & 10 & 5 & 1.644 & 0.822 \\
\hline Total & 100 & 182.5 & 16.439 & 30.001 \\
\hline
\end{tabular}


equivalent content, just as in Figures 4 and 5 . In the Column (2) these values have been converted to $\mathrm{mg}$ ions; this column totals 182.5. For an osmotic pressure of $0.71 \mathrm{~atm}$, the total ionic concentration must be $30 \mathrm{mg}$ ion per litre. The absolute amounts of each ions as milliequivalents per litre are obtained by multiplying the values in the first column by $30 / 182.5$ (giving a total of $30 \mathrm{mg}$ ions per litre); the values are given in Column (3). As a check, these values have been re-converted in Column (4) into $\mathrm{mg}$ ions per litre, and the required total of 30 is confirmed.

Summing up, it will be seen that Column (3) gives the number of milliequivalents per litre of each ion corresponding to a particular relative ratio of anions and of cations and a total ionic concentration of $30 \mathrm{mg}$ ions per litre. Thus, except for $\mathrm{pH}$, the solution prepared according to this formula satisfies all requirements.

In order to apply the formula to actual salts, a scheme has been devised which enables the procedure to be followed systematically and which utilizes the smallest number of different salts, giving preference to those which are easily soluble. For most formulae this has meant 5 different salts, but there is a smaller group requiring 4 salts and a very small group, 6 salts. Details of the system applied to solution Combination $I a$ are outlined in Table 2 .

TABI.I: 2

\begin{tabular}{|c|c|c|c|c|c|c|c|c|}
\hline \multirow{2}{*}{\multicolumn{3}{|c|}{ Combination ta $\{30 \mathrm{mg}$ ions 1 , }} & \multicolumn{6}{|c|}{ Hillicquivalents per litre } \\
\hline & & & \multirow{2}{*}{$\frac{k^{+}}{13.151}$} & \multirow{2}{*}{$\frac{\mathrm{C}^{4++}}{1.644}$} & \multirow{2}{*}{$\begin{array}{l}\mathrm{M} \mathrm{s}^{++1} \\
1.644\end{array}$} & \multirow{2}{*}{$\frac{\mathrm{NO}_{3}^{-}}{13.151}$} & \multirow{2}{*}{$\frac{\mathrm{H}_{2} \mathrm{PO}_{4}^{-}}{0.822}$} & \multirow{2}{*}{$\frac{\mathrm{SO}_{4}^{--}}{2.466}$} \\
\hline Salt & $\begin{array}{l}\text { Norma- } \\
\text { lity }(N)\end{array}$ & $\begin{array}{c}\text { ml per } \\
101\end{array}$ & & & & & & \\
\hline $\mathrm{KH}_{2} \mathrm{PO}_{4}$ & 1 & 8.22 & 0.822 & & & & 0.822 & \\
\hline $\mathrm{C}:\left(\mathrm{H}_{2} \mathrm{PO}_{4}\right)_{2} \cdot \mathrm{Iaq}$. & 0.1 & & & & & & & \\
\hline $\mathrm{Mg}\left(\mathrm{H}_{3} \mathrm{PO}_{4}\right)_{2} .3 \mathrm{aq}$. & & & & & & & & \\
\hline $\mathrm{Ca}\left(\mathrm{NO}_{3}\right)_{2} .4 \mathrm{aq}$ & 10 & 1.644 & & 1.644 & & 1.644 & & \\
\hline $\mathrm{CaSO}_{4}$ & 0.02 & & & & & & & \\
\hline $\mathrm{HgSO} .7 \mathrm{aq}$ & 2 & 8.22 & & & 1.644 & & & 1.644 \\
\hline $\mathrm{IIg}\left(\mathrm{NO}_{3}\right)_{2} .6 \mathrm{ng}$ & 1 & & & & & & & \\
\hline $\mathrm{KNO}_{3}$ & 1 & 115.07 & 11.507 & & & 11.507 & & \\
\hline $\mathrm{K}_{2} \mathrm{SO}_{4}$ & 1 & 8.22 & 0.822 & & & & & 0.822 \\
\hline
\end{tabular}

As far as possible, the required number of milli-equivalents of the various ions are obtained preferentially from salts in the order, top to bottom; this order is based first on the ease with which the phosphate can be supplied in manageable form, viz $\mathrm{K}>\mathrm{Ca}>\mathrm{Mg}$. The balance of calcium is then made up in the order $\mathrm{NO}_{3}{ }^{-}>\mathrm{SO}_{4}{ }^{--}$, 
and that of magnesium in the order $\mathrm{SO}_{4}^{--}>\mathrm{NO}_{3}{ }^{-}$; any nitrate outstanding is then made up from $\mathrm{KNO}_{3}$. Final amendments, if necessary, are automatically made up by adding equivalent amounts of $\mathrm{K}^{+}$and $\mathrm{SO}_{4}-$.

To facilitate the preparation of these solutions, calculations have been made to determine how many $\mathrm{ml}$ of stock salt solution of given normality are needed per 10 litres of nutrient solution.

Attention is drawn to the difficulty of obtaining a clear solution of $0.02 \mathrm{~N} \mathrm{CaSO}_{4}$ if $\mathrm{CaSO}_{4}$ is used: this can be avoided by dissolving $1 \mathrm{~g} \mathrm{CaCO}_{3}$ in $200 \mathrm{ml} 0.1 \mathrm{~N} \mathrm{H}_{2} \mathrm{SO}_{4}$ and making up to 11 with water after it has dissolved.

In each case, $10 \mathrm{l}$ of the required nutrient solution were prepared using demineralized water (spec. conductivity usually $10^{-6}$ and never $<10^{-5} \mathrm{ohm}^{-1} \mathrm{~cm}^{-1}$ ). The solution was then thoroughly aerated for 24 hours so as to obtain equilibrium with air. The $\mathrm{pH}$ of the resulting solution was measured with a Radiometer $\mathrm{pH}$ meter, Type M22P: all preparations were carried out in the laboratory at a temperature of usually, about $21^{\circ} \mathrm{C}$.

Solution $\mathrm{r} a$ had a $\mathrm{pH}$ value of 4.76 which, after 24 hours aeration, rose to 5.33. One litre of this solution was then titrated to $\mathrm{pH} 5$ with $\mathrm{HNO}_{3}$; the titrations were made with continuous measurements of $\mathrm{pH}$, and agitation by magnetic stirrer. $0.14 \mathrm{ml}$. of $\mathrm{HNO}_{3}(.0838 \mathrm{~N})$ were found necessary to obtain a $\mathrm{pH}$ of 5 ; this is equivalent to $0.012 \mathrm{me} \mathrm{NO}_{3}-$ per litre. Further aliquots of 11 nutrient solution were titrated to obtain the other $\mathrm{pH}$ values $-5.8,6.5,7.1$, and 7.6; the amounts of $\mathrm{KOH}$ required corresponded respectively to 0.060 , $0.296,0.606$ and $0.772 \mathrm{me} \mathrm{K}^{+}$. After each titration, the solutions were again aspirated for 1 hour and the $\mathrm{pH}$ remeasured; these gave new $\mathrm{pH}$ values of $5.03,5.86,6.45,6.85$ and 7.30 respectively. Since it was decided to accept only a deviation of $\pm 0.1 \mathrm{pH}$ units from the required $\mathrm{pH}$ value the solution giving a $\mathrm{pH}$ of 6.85 instead of $7.1 \pm 0.1$ was again titrated with $\mathrm{KOH}$ to $\mathrm{pH} 7.1$; this required a further $0.65 \mathrm{ml}$ of $\mathrm{KOH}(.0837 \mathrm{~N})=0.054 \mathrm{me} \mathrm{K}^{+}$. After aspirating again for 1 hour, the $\mathrm{pH}$ fell to 7.0. The solution giving a $\mathrm{pH}$ of 7.30 instead of $7.6 \pm 0.1$ was similarly retitrated with $\mathrm{KOH}$ and an equivalent of $0.087 \mathrm{me} \mathrm{K}^{+}$was required in this case; after 1hour's aspiration, the $\mathrm{pH}$ rose to 7.34, indicating incomplete dissociation. Further titrations were made and finally, after a total of $0.949 \mathrm{me} \mathrm{K}^{+}$had been added, a solution was obtained which 
after aeration, gave a $\mathrm{pH}$ of 7.54 i.e. within the range $7.6 \pm 0.1$.

Although the solutions at the two highest $\mathrm{pH}$ values were completely clear visually, there wassome indication, as mentioned above, that dissociation was incomplete. Note has been taken of this together with the observation that some of the solutions were opalescent or actually turbid. However, all 320 combinations have been treated in the same way even where incomplete dissociation or precipitation had been expected on theoretical grounds. Although the actual theoretical calculations are beyond the scope of this paper, it can be said that they have given good agreement with the results.

The procedure described so far gives solutions satisfying the $\mathrm{pH}$ requirements but, of course, alters the relative proportions of the anions (where $\mathrm{HNO}_{3}$ was added) or of the cations (where $\mathrm{KOH}$ was added). Furthermore, the total ionic concentration now exceeds the stated $30 \mathrm{mg}$ ions per litre. In order to rectify the ratios the amounts of $\mathrm{NO}_{3}{ }^{-}$or $\mathrm{K}^{*}$ added to adjust the $\mathrm{pH}$ have been converted to equivalents of $\mathrm{NO}_{3}^{-}, \mathrm{H}_{2} \mathrm{PO}_{4}^{-}$and $\mathrm{SO}_{4}^{--}$in the one case or $\mathrm{K}^{+}, \mathrm{Ca}^{++}$and $\mathrm{Mg}^{+-j}$ in the other, in the same proportions as in the original solution. The method of conversion is illustrated below for Solution $\mathrm{Ia}$ (Table 1) with a pH of 6.5 (actually 6.45); to obtain this $\mathrm{pH}, 0.296 \mathrm{mc} \mathrm{K} \div$ (similarly $\mathrm{OH}^{\prime}$ ) had to be added per litre of solution. The conversion factor is obtained from the ratio of the total me cations (including the extra $\mathrm{K}^{+}$) to the original total me cations: -

Conversion factor $=\frac{13.151+1.644+1.644+0.296}{13.151+1.644+1.644}=1.018005$

$1.018005 \times 13.151 \mathrm{me} \mathrm{K}^{+}=13.388 \mathrm{me} \mathrm{K}^{+}$

$1.018005 \times 1.644 \mathrm{me} \mathrm{Ca}^{++}=1.674 \mathrm{me} \mathrm{Ca}^{++}$

$1.018005 \times 1.644 \mathrm{me} \mathrm{Mg}^{++}=1.674 \mathrm{me} \mathrm{Mg}^{++}$

These converted values now give the same relative proportions of $\mathrm{K}, \mathrm{Ca}$, and $\mathrm{Mg}$ as in the original solution and the new formula becomes:

\begin{tabular}{|c|c|c|c|c|c|c|c|}
\hline \multicolumn{1}{|c|}{$\mathrm{K}^{+}$} & $\mathrm{Ca}^{+}$ & $\mathrm{H}_{\mathrm{K}}$ & $\mathrm{NO}_{3}^{-}$ & $\mathrm{H}_{2} \mathrm{PO}_{4}^{-}$ & $\mathrm{SO}_{4}^{--}$ & Total \\
\hline me & 13.388 & 1.674 & 1.674 & 13.151 & 0.822 & 2.466 & - \\
mg ions & 13.388 & 0.837 & 0.837 & 13.151 & 0.822 & 1.233 & 30.268 \\
\hline
\end{tabular}

However, the total ionic concentration has been increased to 
$30.268 \mathrm{mg}$. ions per litre and the formula must therefore be readjusted to give $30 \mathrm{mg}$. ions. The final result is: -

\begin{tabular}{|c|c|c|c|c|c|c|c|}
\hline In & $\overline{\mathrm{K}^{+}}$ & $\mathrm{Ca}++$ & $\mathrm{Mg}^{++}$ & $\mathrm{NO}_{3}^{-}$ & $\mathrm{H}_{2} \mathrm{PO}_{4}^{-}$ & $\mathrm{SO}_{4}^{-}$ & Total \\
\hline me & 13.269 & 1.659 & 1.659 & 13.035 & 0.815 & 2.444 & - \\
mg ions & 13.269 & 0.830 & 0.830 & 13.035 & 0.815 & 1.222 & 30.001 \\
\hline
\end{tabular}

The amounts of the various ions can now be derived from the appropriate salts according to the procedure outlined earlier, making sure that the required surplus of cation $(K)$ is in the first place, made up entirely from $\mathbf{K O H}$; although the surplus cation could also have been supplied as $\mathrm{Ca}(\mathrm{OH})_{2}$ or $\mathrm{Mg}(\mathrm{OH})_{2}, \mathrm{KOH}$ is preferred because of its high solubility. The actual surplus of cations in the final solution amounts to $(13.269+1.659+1.659)-$ $(13.035+0.815+2.444)=0.293 \mathrm{me}$; this is added as $\mathrm{KOH}$ after which the remaining equivalent amounts of cations and anions are added as described earlier.

Ten litres of Solution $\mathrm{x} a$ with $\mathrm{pH} 6.5$ were now prepared according to this new formula. After aeration the $\mathrm{pH}$ changed to 6.58; it is clear that this change in $\mathrm{pH}$ has taken place because of the change from $\mathrm{K}^{+}$to $\mathrm{K}^{+}+\mathrm{Ca}^{++}+\mathrm{Mg}^{++}$. This example, in which $0.815 \mathrm{me}$ $\mathrm{H}_{2} \mathrm{PO}_{4}^{-}$were present and a surplus of $0.293 \mathrm{me} \mathrm{OH}-$ had to be added, will be further discussed later on.

Except for those solutions already turbid or giving a precipitate on titration with $\mathrm{KOH}$, all 320 ion combinations have been converted in this way and tested according to the above scheme at 5 different $\mathrm{pH}$ values.

\section{COMPUTATION OF FORMULAE}

As mentioned earlier there is apparently a systematic relation between the amount of $\mathrm{H}_{2} \mathrm{PO}_{4}^{-}$present in the solution and the surplus $\mathrm{OH}$ ions which must be added in order to obtain a certain $\mathrm{pH}$. This relationship however, is influenced by the relative cation ratios, especially those between $\mathrm{K}^{+}$and $\mathrm{Ca}^{++}$. The $\mathrm{pH}$ depends largely on the ratio of $\mathrm{OH}^{-}$to $\mathrm{H}_{2} \mathrm{PO}_{4}^{-}$ions and this may be depicted by a curve which is displaced according to the $\mathrm{K}$ : Ca ratio.

In the 360 ion combinations, only four $\mathrm{K}: \mathrm{Ca}$ ratios were involved, namely, $80: 10,60: 30,40: 50$ and $20: 70$; however, tests were made on another 80 combinations giving intermediate 
$\mathrm{K}$ : Ca ratios so as to determine with some accuracy, the influence of this ratio on the displacement of the $\mathrm{OH}^{-} \mathrm{H}_{2} \mathrm{PO}_{4}^{-}$curves.

In Figure 6, the $\mathrm{pH}$ (abcissa) is plotted against the amount of

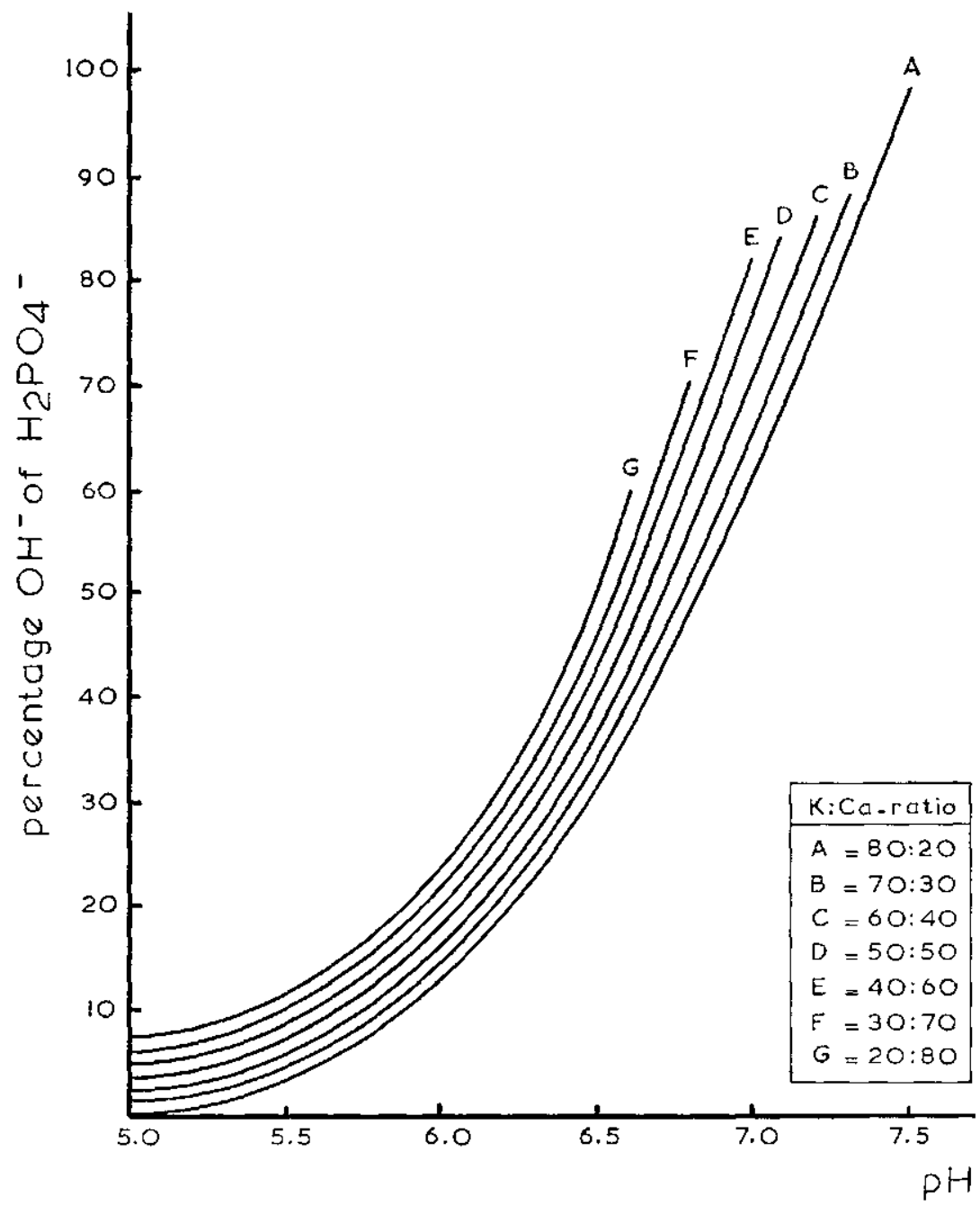

Fig. 6. The dependence of the $\mathrm{OH}^{-}: \mathrm{H}_{2} \mathrm{PO}_{4}^{-}$curves upon the $\mathrm{K}:$ Ca ratio.

$\mathrm{OH}^{-}$expressed as a percentage of the amount of $\mathrm{H}_{2} \mathrm{PO}_{4}{ }^{-}$in the solution (ordinate); curves are given for 7 different $\mathrm{K}: \mathrm{Ca}$ ratios $(A-G)$, and intermediate values can be obtained by interpolation. The curves illustrated however are on too small a scale for practical 
purposes and larger scales are available for those who wish to use them.

With the aid of these curves, it is now possible to work out any desired formula. Suppose we require a ratio (in equivalents) of $\mathrm{NO}_{3}^{-}: \mathrm{H}_{2} \mathrm{PO}_{4}^{-}: \mathrm{SO}_{4}^{--}=5: 3: 1$ (i.e. $55.556: 33.333: 11.111$ to give a total of 100 ) and a ratio of $\mathrm{K}^{+}: \mathrm{Ca}^{++}: \mathrm{Mg}^{++}=50: 30: 20$, with a total ionic concentration of $30 \mathrm{mg}$ ions and a $\mathrm{pH}$ of 6.3 .

The ratio $\mathrm{K}: \mathrm{Ca}=5: 3$ or $62.5: 37.5$ (to give a total of 100) and the line $\mathrm{C}$ in Figure 6, representing a ratio of $60: 40$, is the nearest to this. For $\mathrm{pH} 6.3$ this would indicate an $\mathrm{OH}^{\prime}$ requirement of 26.9 per cent of the phosphate content. Interpolation between curves $\mathrm{C}$ and $\mathrm{B}$ to correspond with the actual $62.5: 37.5$ ratio, indicates a somewhat lower value, namely, 26.0 per cent; this is the value adopted.

In the desired solution, $\mathrm{H}_{2} \mathrm{PO}_{4}{ }^{-}$amounts to 33.333 per cent of the total equivalent anion content so that the $\mathrm{OH}^{-}$corresponding to 26.0 per cent of this, amounts to $8.667 \mathrm{OH}$ ions. These $\mathrm{OH}$ ions are now divided among the cations in the same proportion as the cation ratio, i.e. $50: 30: 20$. This yields $4.333 \mathrm{~K}^{+}, 2.600 \mathrm{Ca}^{++}$and $1.733 \mathrm{Mg}^{++}$and when these amounts are added to the corresponding components of the original cation ratio (total 100), the ratio still holds good. Thus, both cation and anion contents have now been expressed in terms of milliequivalents:-

\begin{tabular}{|c|c|c|c|c|c|}
\hline $\mathrm{K}^{+}$ & $\mathrm{Ca}^{++}$ & $\mathrm{Mg}^{++}$ & $\mathrm{NO}_{3}^{-}$ & $\mathrm{H}_{2} \mathrm{PO}_{4}^{-}$ & $\mathrm{SO}_{4}^{--}$ \\
\hline 54.333 & 32.600 & 21.733 & 55.556 & 33.333 & 11.111 \\
\hline
\end{tabular}

In order to obtain a total ionic concentration of $30 \mathrm{mg}$ ions, the above values are first converted into $\mathrm{mg}$ ions: -

\begin{tabular}{|c|c|c|c|c|c|c|}
\hline $\mathrm{K}^{+}$ & $\mathrm{Ca}^{++}$ & $\mathrm{Mg}^{++}$ & $\mathrm{NO}_{3}^{-}$ & $\mathrm{H}_{2} \mathrm{PO}_{4}{ }^{-}$ & $\mathrm{SO}_{4}^{--}$ & Total \\
\hline 54.333 & 16.300 & 10.867 & 55.556 & 33.333 & 5.556 & 175.945 \\
\hline
\end{tabular}

Since the total of 175.945 has to correspond to $30 \mathrm{mg}$ ions, the final formula is obtained by multiplying throughout by $30 / 175.945$. The result is a formula for a nutrient solution satisfying the following conditions: -

(1) a desired relative anion ratio

(2) a desired relative cation ratio

(3) a desired total ionic concentration

and (4) a desired $\mathrm{pH}$ with a maximum tolerance of $\pm 0.1 \mathrm{pH}$. 
Assuming that the nutrient solution is prepared according to this formula, the $\mathrm{pH}$ after aeration will be about 6.37 i.e. only 0.07 units higher than required.

In the case of solution $1 a$, which has been given earlier as an example, the amount of $\mathrm{OH}^{-}$added $(0.293 \mathrm{me}$ ) corresponds to 35.9 per cent of the amount of $\mathrm{H}_{2} \mathrm{PO}_{4}-(0.815$ me) present in the solution; according to curve $\mathrm{A}$ in Figures 6 , this would indicate a pH of about 6.58 , which agrees exactly with that actually found.

Every possibly ion combination having a total concentration of $30 \mathrm{mg}$ ions, which does not produce a precipitate, can be prepared in this way within a $\mathrm{pH}$ range covered by the $\mathrm{K}$ : Ca ratios Precipitates, if any, and the significance of the above-mentioned $\mathrm{pH}$ range will be discussed later.

Regarding the extent to which the $\mathrm{pH}$ of the solution satisfies the required value, it must be stated that no better accuracy than $\pm 0.2 \mathrm{pH}$ units can be guaranteed within the range 5.0 to 5.5. This is due to the fact that between these values, the phosphate dissociation curve runs practically horizontal, in other words, the smallest change in $\mathrm{OH}^{-}$concentration produces a large change in $\mathrm{pH}$. Between $\mathrm{pH} 5.5$ and 6.0 , the precision is \pm 0.15 and between $\mathrm{pH}$ 6.0 and 7.0, \pm 0.1 . Because of the incomplete dissociation of $\mathrm{CaHPO}_{4}$, and other salts above $\mathrm{pH} 7,0$, the accuracy falls to $上 0.2$.

The method does not hold for extreme values or for solutions not containing calcium or phosphate.

It will be observed in Figure 6 that the curves cover only a certain $\mathrm{pH}$ range with a minimum at $\mathrm{pH} 5.0$; relationships below this value were, in fact, not investigated. However, between $\mathrm{pH}$ 4.0 and 5.0, there is little point to the investigation since the dissociation curve for $\mathrm{H}_{2} \mathrm{PO}_{4}{ }^{-} \rightleftharpoons \mathrm{HPO}_{4}{ }^{--}$then runs horizontally and in this region the solution is no longer buffered by phosphate. Below $\mathrm{pH} 4.0$, the accuracy increases again (ct Figure 1). Above the $\mathrm{pH}$ range covered by the curves, few solutions are possible with a total ionic concentration of $30 \mathrm{mg}$ ions per litre; only in the case of extreme ratios are higher $\mathrm{pH}$ values possible e.g. in solutions containing very little $\mathrm{Ca}$. This is because of the occurrence of turbidity or actual precipitation. Nevertheless, a few solutions are still possible with $\mathrm{pH}$ values greater than those indicated by the curves, but these require more $\mathrm{OH}$ ions than would normally be necessary to achieve the desired $\mathrm{pH}$. In such cases, the dissociation 
of certain ion combinations is also very incomplete and a stage is finally reached when the addition of $\mathrm{OH}$ ions does not produce any rise in $\mathrm{pH}$ but even a fall, because of precipitation of $\mathrm{CaHPO}_{4}$ and other compounds. Even within the $\mathrm{pH}$ range covered by the curves, certain combinations are also not possible because of precipitation. On the whole, about 58 per cent of all possible combinations can be used around the point where the appropriate curve ends. Also near the 'lower' regions of the curves, a number of combinations are not possible; for Curve $A$, this involves about 15 per cent of all possible combinations at $\mathrm{pH} 7.1$ and for Curve $\mathrm{C}$, about 15 per cent at $\mathrm{pH} 6.5$.

Whether a particular combination at a certain $\mathrm{pH}$ is possible or not, can be determined with some precision. No combination with the product of $\mathrm{Ca}^{++}$and $\mathrm{SO}_{4}{ }^{--}$greater than $60 \mathrm{mg}$ ions per litre is possible, independent of the $\mathrm{pH}$ of the solution. However, this concerns only a few combinations; in Figures 4 and 5 , it applies only to the Anion Ratios $I 6$ and $I 7$ in combination with Cation Ratios $m$ and $n$. Solutions with the product of $\mathrm{Ca}^{++}$and $\mathrm{HPO}_{4}{ }^{--}$ amounting to about $2.2 \mathrm{mg}$ ions per litre are also doubtful; if $\mathrm{Ca}^{++}$ $\times \mathrm{HPO}_{4}{ }^{--}$is greater than 2.2, the solution becomes turbid. There are however, border-line cases in which precipitation may or may not occur depending on the other ratios. The absolute contents of $\mathrm{Ca}^{++}$and total phosphate are readily determined from the formula calculated; the absolute content of $\mathrm{HPO}_{4}{ }^{-}$may then be found from its percentage of the total phosphate read from the phosphate dissociation curves in Figure 1, at the appropriate $\mathrm{pH}$.

The method described above holds good for a total ionic concentration of $30 \mathrm{mg}$ ions per litre. Although the immediate objective of this investigation has therefore been achieved, tests have also been made on solutions with a total ionic concentration of $20 \mathrm{mg}$. ions per litre $(0.47 \mathrm{~atm}$ osmotic pressure). In these cases also, the curves can be used with a certain accuracy. No tests have been made on solutions with lower concentrations; in any case, this must be looked upon as a separate investigation since the curves need then to be extended to regions of higher $\mathrm{pH}$. At these lower concentrations, many more combinations are possible, especially at the higher $\mathrm{pH}$ values.

When the total ionic concentration is raised above $30 \mathrm{mg}$ ions per litre, only a limited number of combinations are possible. Thus, 
at $1 \mathrm{~atm}$ osmotic pressure (about $42 \mathrm{mg}$ ions per litre), only a few nutrient solutions can be made, viz. only the cation combinations $a, b, c$ and $d$ (Figure 5) in combination with certain anion ratios. Above $\mathrm{pH}$ 6.5, only very few extreme ion ratios are still possible.

In this publication, only 3 anions and 3 cations have been investigated. Tests have been made as to the possibility of including a fourth cation, $\mathrm{Na}$; in this case, the same $\mathrm{K}$ : Ca ratio can be used, but taking $(\mathrm{K}+\mathrm{Na})$ : $\mathrm{Ca}$ into account instead, i.e. the sum of sodium and potassium is treated as potassium. As far as we have been able to determine, this does not upset the reliability of the method. The calculations involving four cations are identical with those for three. No investigation has yet been made as to whether $\mathrm{NH}_{4}$ ions, for example, can be dealt with by the same curves; in this case much more attention would be necessary to those combinations producing precipitates.

\section{SUMMARY}

So as to provide a basis for nutritional and general physiological experiments on plants, a systematic investigation has been made into the preparation of nutrient solutions satisfying certain requirements as to the relative ratios of the nutrient ions, the total ionic concentration and the $\mathrm{pH}$, without complications due to precipitation. A method has been developed whereby it is possible to compute in advance, a formula for the composition of the nutrient solution which satisfies these requirements.

\section{ACKNOWLEDGEMENT}

The author is much indebted to Dr. L. Leyton 1)epartment of Forestry, Imperial Forestry Institute, University of Oxford, for reading and improving the text of this paper.

Received Oetober 28, 1960

\section{LITERATURE CITED}

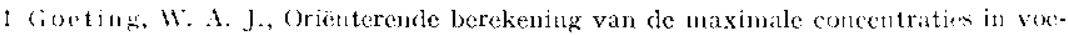
(lingsoplessingen vore plantenteclt zonder aarde. Algencne Technische Afdeling T.X.O. kapport T I:B:3 (1949).

2 Hewitt, IE. J., Sand ancl water culture methods used in the study of plant mutrition. Commonweat th Burean of Hort. Plantation Crops, Tech. Comnum. No. 2a (1952).

3 Kiplinger, D. C. and I,aurie, A., Crowing ormamental greenhouse crops in gravel culture. Ohio Agr. IExp. Sta. I3ull. 6:3/ (1942).

4 Schropp, W., Der Vegetationsversuch I. Jie Methodik der Wasserkultur höherer Pflanzen. Neumann Verlag, Radebuel und Berlin (1951.)

5 Steiner, A. A., Problenen rond de $\mathrm{K}: X$ verhoukling, Kali 35, 186-188 (1958). 